\title{
DISERTACIONES
}

ENSAYOS

Para citar este artículo: Fernández Jiménez, A. (2021). El romance periodístico de Jaime Campmany como modelo de periodismo literario en la España de finales del siglo xx. Anuario Electrónico de Estudios en Comunicación Social "Disertaciones", 14(1), 1-22. https://doi.org/10.12804/revistas.urosario.edu.co/ disertaciones/a.8462

\section{EL ROMANCE PERIODÍSTICO DE JAIME CAMPMANY COMO MODELO DE PERIODISMO LITERARIO EN LA ESPAÑA DE FINALES DEL SIGLO XX}

\section{The Journalistic Romance of Jaime Campmany as a Literary Journalism Model in Spain in the Late 20th Century \\ O romance jornalístico de Jaime Campmany como modelo de jornalismo literário na Espanha no final do século xx}

Antonio Fernández Jiménez, Universidad de Murcia (España)

antonio.fernandez15@um.es

\section{Recibido: 17 de noviembre de 2019}

Aceptado: 23 de mayo de 2020

Fecha de prepublicación: 30 de septiembre de 2020

\section{RESUMEN}

En este trabajo se da a conocer a grandes rasgos la última etapa profesional del periodista Jaime Campmany (1925-2005), que ocupa las tres últimas décadas de la pasada centuria, y donde destacamos la que consideramos una de las aportaciones más originales al periodismo literario de aquellos momentos: los romances periodísticos. Columnas de opinión construidas en endecasílabos. Se trata de una creativa forma de contar, opinar y versificar la actualidad en un período de la historia de España y del periodismo en que se está cultivando con especial ahínco 


\section{DISERTACIONES}

ENSAYOS

Los desafios del periodismo narrativo

ISSN: 1856-9536

Doi: https://doi.org/10.12804/revistas.urosario.edu.co/disertaciones/a.8462

Volumen 14, Número 1 / Enero-junio 2021

Versión PDF para imprimir desde

http://revistas.urosario.edu.co/index.php/disertaciones

la columna de opinión, con el advenimiento de la democracia y las libertades logradas. Este género goza de una supremacía tal que algunos autores han considerado que es un tiempo, que arranca aproximadamente a partir de 1975, en el que comienza a gestarse un nuevo periodismo donde la columna proliferará como nunca antes. Este artículo analiza las características de los romances de Campmany, que se han reducido básicamente a tres puntos: estirpe clásica (una vasta cultura), virtuosismo léxico (despliegue de vocablos cultos y populares) y humorismo (socarronería e ironía en los argumentos). Con estas premisas teóricas, aportamos además una muestra de cinco romances para ejemplificar y comprobar lo expuesto, además de destacar que Campmany rescata y actualiza la tradición de periodistas versificadores.

Palabras clave: Jaime Campmany; periodismo literario; columna periodística; historia del periodismo español; libertad de expresión.

\section{ABSTRACT}

In this article, the last period of the career of journalist Jaime Campmany (1925-2005) is revealed in broad strokes. This period covers the last three decades of the last century. We highlight what we consider one of the most original contributions to the literary journalism of those times: 'the journalistic romances', opinion columns written in hendecasyllables. It was a creative way of giving opinions and versifying 1) the current time in a period of the history of Spain and 2) journalism in which the opinion column was being developed wholeheartedly and soulfully, owing to the democracy and freedom achieved. This genre enjoyed such supremacy that some authors considered this a phase that began approximately in 1975 , when a new type of journalism began to take shape, with columns rapidly proliferating. In this article, the characteristics of Campmany's romances have been analyzed and summarized into three points: classic lineage (a vast culture), lexical virtuosity (the development of educated and popular terms), and humourism (sarcasm and irony in arguments). With these theoretical premises, we contribute further a sample of five romances to exemplify and prove what has been explained, apart from emphasizing that Campmany rescued and revised the tradition of journalists who versify.

Keywords: Jaime Campmany; literary journalism; newspaper column; history of Spanish journalism; freedom of speech.

\section{RESUMO}

Nesta obra, é amplamente divulgada a última etapa profissional do jornalista Jaime Campmany (1925-2005), que ocupa as últimas três décadas do século passado, e onde destacamos o que consideramos ser uma das contribuições mais originais para o jornalismo literário desses momentos: romances jornalísticos. Colunas de opinião construídas em hendecasílabos. É uma forma criativa de contar, exprimir opiniões e verificar a atualidade de um período da história da Espanha e do jornalismo em que a coluna de opinião se cultiva com especial zelo, desde o advento da democracia e das liberdades conquistadas. Este gênero goza de tal supremacia que alguns autores 


\section{DISERTACIONES}

ENSAYOS

Los desafios del periodismo narrativo

ISSN: 1856-9536

Doi: https://doi.org/10.12804/revistas.urosario.edu.co/disertaciones/a.8462

Volumen 14, Número 1 / Enero-junio 2021

Versión PDF para imprimir desde

http://revistas.urosario.edu.co/index.php/disertaciones

o consideram um momento, que se inicia aproximadamente a partir de 1975, quando um novo jornalismo começa a se formar onde a coluna se proliferará como nunca. Este artigo analisa as características dos romances de Campmany, que foram basicamente reduzidos a três pontos: linhagem clássica (uma vasta cultura), virtuosismo lexical (exibição de palavras cultas e populares) e humor (astúcia e ironia nas discussões). Com essas premissas teóricas, fornecemos também uma amostra de cinco romances para exemplificar e verificar o exposto, além de destacar que Campmany resgata e atualiza a tradição de versar jornalistas.

Palavras-chave: Jaime Campmany; jornalismo literário; coluna de jornal; história do jornalismo espanhol; liberdade de expressão.

\section{Introducción}

\section{Un viejo género en actualidad}

En los años ochenta y noventa del pasado siglo xx, el periodismo literario español se cultiva en los géneros de opinión, especialmente en la columna periodística. De modo que "lo que ha constituido el sello distintivo de los nuevos periodistas españoles ha sido su común voluntad de estilo, la convicción de que solo una escritura periodística de calidad es capaz de dar cuenta de la compleja cambiante realidad social" (Vela, 2009a, p. 786). Y una de las aportaciones más originales de aquel tiempo, que desentrañaremos en este artículo, fue el romance periodístico de Jaime Campmany (Murcia, 1925-Madrid, 2005), una creativa fórmula periodístico-literaria que recupera y actualiza la tradición de periodistas versificadores del siglo xıx y principios del xx, tales como Selgas, Zorrilla o Luis de Tapia. ${ }^{1}$

Recuerda Ramón Menéndez Pidal en su libro Flor nueva de romances viejos que "España es el país del Romancero. El extraño que recorre la Península debe traer en su maleta, según consejo de cierto viajero entendido, un Romancero y un Quijote, si quiere sentir y comprender bien el país que visita" (1989, p. 9). Y se pregunta Menéndez Pidal qué razones existen para afirmar que el romance es representativo del pueblo español y no tanto de otros países; y, entre otras cosas, destaca que es así porque "la antigua epopeya española se distingue de las otras por tener un campo de inspiración más moderno que todas" (1989, p. 9). Es decir, “los temas conservados en la épica

1 Juan Cantavella analiza en el artículo "La columna en verso: recuerdo y presencia de poetas y versificadores", publicado en Doxa Comunicación (2011), la práctica del romance en periodistas decimonónicos y del siglo xx, tales como Manuel del Palacio, Luis de Tapia, Raimundo de los Reyes, Alfonso Ussía y también Jaime Campmany. 


\section{DISERTACIONES}

ENSAYOS

Los desafios del periodismo narrativo

ISSN: 1856-9536

Doi: https://doi.org/10.12804/revistas.urosario.edu.co/disertaciones/a.8462

Volumen 14, Número 1 / Enero-junio 2021

Versión PDF para imprimir desde

http://revistas.urosario.edu.co/index.php/disertaciones

española van desde el siglo VIII, con el rey Rodrigo, hasta el xI, con el Cid, y aun hasta el XII, con Alfonso VII y el rey Luis de Francia" (1989, p. 9). Y esto quiere decir que "España se manifiesta más tenaz, más tradicionalista en mantener en actualidad un viejo género" (1989, p. 10).

Jaime Campmany resucita de la tradición literaria española un viejo género para darle sentido actual en el periódico y en la radio; para ponerlo de moda. "Jaime Campmany es hoy - dijo en 1995 Jiménez Losantos-quien más y mejor protagoniza este revivir, a la vez culto y popular, del romance” (1995a, p. 13). ${ }^{2}$ Los asuntos de actualidad de sus romances "se inclinan hacia la política, otros hacia la cultura, el deporte o los chismes de sociedad, y otros hacia el cachondeo" (Campmany, 1997, p. 23). Romance de ciegos, el primero, publicado en ABC en 1984, tuvo una repercusión inesperada. "La recepción positiva que se obtiene de los lectores se acentúa de forma muy destacada cuando un escrito se presenta de esta manera tan original y poco frecuente. El público aprecia de forma inmediata el ingenio que se derrocha y la habilidad de juntar ideas y asonancias" (Cantavella, 2011, p. 79). Campmany llegó a recibir "cartas de lectores que se habían quedado prendados de aquella novedad, que la consideraban atractiva" (Cantavella, 2011, p. 80).

Explica Tomás Loba que el romancero en general ha estado determinado por "la intrahistoria, por citar el término noventayochista, la cual ha modelado, generado o fusionado romances para dejarlos fosilizados en las páginas de algún cancionero (y) adaptarse progresivamente a la época que le toca vivir" (2009, pp. 15-16). Con sus romances, Campmany 'fosiliza' intrahistorias de la España de las dos últimas décadas del pasado siglo, ${ }^{3}$ pues las técnicas narrativas del romance facilitan que la actualidad pasajera se torne en atemporal. Esa es la meta del periodismo literario: "Las artes estilísticas y de construcción narrativa asociadas desde siempre con la literatura de ficción ayudan a atrapar la fugacidad de los acontecimientos, que es la esencia del periodismo" (Kramer 1995, citado por Pan \& Baceiredo, 2010, p. 22).

Así, podríamos considerar estos romances como la actualización de fenómenos protoperiodísticos, ya que por medio de una dispositio atractiva impregnan de fuerza comunicativa el relato de hechos. "En el periodismo antiguo -el periodismo de los siglos xVII, xvIII y comienzos del xix - no prevalecía el concepto actual de tempestividad extrema (no importaba saber las cosas inmediatamente después de acaecidas, sino que era más importante conocerlas bien, sin apresuramiento)" (Casasús \& Núñez, 1991, p. 17). Uno de los mayores estudiosos de este género de opinión en España es Fernando López Pan, quien entiende que la columna de opinión de estilo muy personal, como las de Campmany, "quedan cómodamente acogidas entre los géneros periodísticos de autor; en los que también encuentra acomodo la vertiente literaria de la columna a través del subgénero del periodismo literario" (2008, p. 66).

2 Se trata del prólogo de Federico Jiménez Losantos "Aquí llega Jaime Campmany con su romance bajo el brazo" para El libro de los romances de Jaime Campmany (1995). En adelante en cada referencia en el texto entre paréntesis se citará no al autor del libro, sino al del prólogo: Jiménez Losantos (1995a).

3 En 2004, un año antes de su muerte, Campmany había decidido romancear toda la historia de España. Ese año saca su primer volumen: Romancero de la historia de España. De Atapuerca a los Reyes Católicos. El periodista Antonio Astorga dijo que "narrar la Historia sin hacer una ficción poética y hacer mester de juglaría relatando episodios históricos sin inventarlos ni tergiversarlos" (ABC, 14 de junio de 2005, p. 12) fue el objetivo de Campmany. Sin embargo, falleció a falta de dos volúmenes para cerrar toda la historia de España. 


\section{DISERTACIONES}

ENSAYOS

Los desafios del periodismo narrativo

ISSN: 1856-9536

Doi: https://doi.org/10.12804/revistas.urosario.edu.co/disertaciones/a.8462

Volumen 14, Número 1 / Enero-junio 2021

Versión PDF para imprimir desde

http://revistas.urosario.edu.co/index.php/disertaciones

El objetivo de este trabajo estriba en desentrañar el concepto de romance periodístico en Jaime Campmany, analizando para ello sus puntos característicos y dando a conocer una muestra representativa de esta forma creativa de escribir artículos de opinión en octosílabos, que, según explicó su autor, están más cerca de la lengua hablada (Jiménez Losantos, 1995a). Esto supone el empleo de un lenguaje periodístico donde priman claridad, sencillez, narración y hasta poesía; pues tradicionalmente estos breves poemas eran "recitados y cantados en sermo vulgaris, en la lengua con la que solía el pueblo fablar con su vecino" (Jiménez Losantos, 1995a, p. 10).

\section{El periodismo literario en el último tercio del siglo xx}

"El artículo se ha convertido en el género identitario de la literatura española del siglo xx" (Gross, 2010, p. 118). En 1984, fecha en la que Campmany comienza a publicar sus romances en el diario $A B C$, la prensa española gozaba ya de cuatro años de plena libertad de expresión con la llegada de la democracia, de modo que el género de opinión, manifestado especialmente en las columnas periodísticas, triunfaba en los periódicos en una gran bocanada de libertad después de un largo período de censura. Las libertades devenidas de la Transición, el llamado nuevo periodismo americano y el mayo del 68 son algunos de los factores contextuales que influyeron en el nuevo estilo de hacer periodismo, ya que se ponen en cuestión las pautas de escritura de los medios de comunicación ortodoxos. ${ }^{4}$

En España aparecieron los primeros indicios de una "escritura informativa de creación" (Vela, 2009b, p. 697), cuyos autores más representativos fueron Francisco Umbral, Manuel Vicent, Jaime Campmany, Rosa Montero, Manuel Vázquez Montalbán, etc. El objetivo de estos periodistas literarios era desviarse con respecto al periodismo tradicional y aceptar "las técnicas literarias como válidas para el periodismo. Se busca apasionar al lector, conseguir la comunicación emotiva sin necesidad de que el mundo sea ficcional, sino mostrando la actualidad como contenido" (Vela, 2009b, p. 697). Dice el columnista Raúl del Pozo que la historia de la columna de opinión es la "de unos desobedientes que quemamos el libro de estilo [...] Ahora dicen que la columna narra cada día la historia de España. Antes decían, despectivamente, que era un nicho o una guinda en el pastel”. ${ }^{5}$

4 Cabe señalar que "las influencias del nuevo periodismo español no son tanto las del new journalism americano inaugurado por Tom Wolfe, sino que "hay que buscarlas más en la recuperación de la tradición periodístico-literaria española de Larra o Galdós” (2009, p. 786). En España el periodismo literario se cultiva más en "los géneros de opinión y ensayo: columna, retrato, cuadro de costumbres y artículo" (2009, p. 786), antes que en textos interpretativos, como la crónica o el reportaje, ambos muy desarrollados y con más tradición en Estados Unidos y Latinoamérica (Albalad, 2018).

5 Fragmento citado por Antonio López Hidalgo (2012, p. 18). 


\section{DISERTACIONES}

ENSAYOS

Los desafios del periodismo narrativo

ISSN: 1856-9536

Doi: https://doi.org/10.12804/revistas.urosario.edu.co/disertaciones/a.8462

Volumen 14, Número 1 / Enero-junio 2021

Versión PDF para imprimir desde

http://revistas.urosario.edu.co/index.php/disertaciones

"El artículo o columna es, así pues, un género periodístico de alta intensidad retórica, por tanto de naturaleza básicamente persuasiva [...] La retórica clásica ya considera que el 'ornatus', el tratamiento literario, es un instrumento de primer orden para el éxito persuasivo" (Gross, 2010, p. 119). ${ }^{6}$ El modo en que se escribe en los periódicos en el último tercio del siglo xx va a estar marcado, pues, por una notable "voluntad de estilo" (Vela, 2009a, pp. 785-786) para contar la realidad del país.

Campmany instala sus romances periodísticos en esta nueva realidad que atraviesa la prensa española; $y$, en palabras de Francisco Umbral, "abandona el estilo lírico de la posguerra [...] y deja correr de sí una prosa castiza, dialectal, faltona, divertida, académica y de mala leche". ' Así, en este trabajo se buscará, en palabras de Umbral, "al gramático latino, al latino pardo, al gatopardo, al castellano clásico y al castellano cheli y puede que también al murciano dialectólogo que se sabe palabras de la huerta". ${ }^{8}$

\section{Campmany como modelo de periodista literario ${ }^{9}$}

Cuando en 1977 Guillermo Luca de Tena, a la sazón director de $A B C$, lo fichó para su periódico, Jaime Campmany ya era conocido por su garbo literario, y con esa descripción le daban la bienvenida: "Se incorpora hoy a $A B C$, como cronista parlamentario, una de las plumas más brillantes de esta hora”. ${ }^{10}$ Su relación con la poesía y los periódicos, que tiene su inicio a temprana edad, en la Murcia de los años cuarenta, le hizo forjarse un estilo lírico y particular. Con apenas 18 años, comienza a destacar su figura en el panorama cultural murciano más como poeta que como periodista. En la prensa de su ciudad (La Verdad, Línea, Hoja del Lunes) publica sus primeros versos, pero también sus primeros artículos periodísticos, que no abandonan el ritmo de la lírica y la naciente concepción de un periodismo traspasado por la prosa poética. ${ }^{11}$

6 Siguiendo a López Hidalgo cuando cita a Susana González Reyna (2012, pp. 43-45), podemos hacer una breve distinción entre artículo y columna: "Para González Reyna, tanto el artículo como la columna reflejan la interpretación personal del periodista respecto de los acontecimientos. Sin embargo, establece algunas diferencias. Para la autora, el articulista persigue establecer una tesis, defender o atacar una posición. Por el contrario, el columnista pretende dar a conocer sus opiniones personales en torno de un acontecimiento específico. De esta exposición se suele deducir que el artículo de fondo es más profundo y complejo que la columna. Por ello, el propósito de ambos géneros es distinto".

7 El Cultural, 28 de febrero de 2001.

8 Idem.

9 Este trabajo de investigación es parte de un proyecto mayor materializado en una tesis doctoral que estudia el periodismo literario de Jaime Campmany y Díez de Revenga (Murcia, 1925-Madrid, 2005) a través de sus distintas etapas profesionales: desde sus comienzos en la poesía y el periodismo en su Murcia natal en los años cuarenta del siglo xx, hasta sus últimas columnas periodísticas en los albores del siglo xxı.

$10 A B C, 26$ de octubre de 1977, p. 9.

11 Para conocer más detalles acerca de esta primera etapa de Campmany, puede consultarse el artículo de Antonio Fernández Jiménez "Murcia: tierra y corazón de Jaime Campmany" (Mvrgetana, № 135, pp. 171-193, 2016. http://www.regmurcia.com/docs/murgetana/N135/N135-07.pdf). 


\section{DISERTACIONES}

ENSAYOS

Los desafios del periodismo narrativo

ISSN: 1856-9536

Doi: https://doi.org/10.12804/revistas.urosario.edu.co/disertaciones/a.8462

Volumen 14, Número 1 / Enero-junio 2021

Versión PDF para imprimir desde

http://revistas.urosario.edu.co/index.php/disertaciones

En 1952 marcha a Madrid para dedicarse de lleno al periodismo. Escribe en numerosas publicaciones, como Juventud, Arriba, El Español, desde artículos literarios hasta críticas de teatro, crónicas de viajes y de fútbol, reportajes narrativos y necrológicas. Estos textos se enmarcan en una época de la historia del periodismo español como es la de los años cincuenta, donde la escritura periodística es heredera directa del estilo de una generación de periodistas - del 27-, algunos en activo en esta segunda década de la posguerra, quienes "inundaron las páginas de los periódicos con un periodismo literario de calidad que va a marcar toda una época" (Gutiérrez, 2009, p. 335). El modo de hacer periodismo de aquellos autores -César González Ruano, Ramón J. Sender, Ernesto Giménez Caballero, Enrique Díez Canedo, Eugenio Montes, Eugenio D’Ors, Josep Pla, Agustín de Foxá, Chaves Nogales o José María Pemán, entre otros- caló en la generación de jóvenes periodistas que comenzaban su carrera en los periódicos en los años cincuenta, como Umbral, Alcántara o Campmany. Y es que el modelo de artículo literario que se consolida en la posguerra "definiría el modelo de artículo literario del que vivimos aún hoy" (San Juan, 2009, p. 519).

Entre 1966 y 1971, después de regresar Campmany de Roma, donde había estado trabajando cuatro años como corresponsal para la Agencia Pyresa y cuya estancia supuso para él, en palabras de Umbral, "un baño de Renacimiento" 12 porque pudo experimentar la libertad de una democracia, comenzaría su propia transición democrática con unos artículos diarios en Arriba, conocidos como 'Pajaritas de papel'. Gozaron del aplauso de los lectores tanto por su belleza lírica como por la valía de hablar abiertamente, sin tapujos, citando a poetas que seguían siendo mirados con recelo por la censura. ${ }^{13}$

A partir de los años setenta, su periodismo estará exclusivamente dedicado a la columna de opinión, primero en Informaciones y Hoja del Lunes, y a partir de 1977 en ABC. Como dice su hijo Emilio Campmany, en ese tiempo su padre "pudo escribir con una libertad que nunca había tenido años atrás, no porque en la Prensa del Movimiento no hubiera escrito lo que él hubiera querido, sino porque inevitablemente te impedían enfrentarte abiertamente y exponer con claridad las ideas". ${ }^{14}$ De modo que con el romance expresa al fin con libertad la actualidad, versificándola de forma socarrona y desplegando un caudal de ingenio, humor y verborrea que, al igual que la 'Pajarita', fue muy aplaudido por los lectores, además "de popularizar esta forma métrica" y lograr que "otros columnistas le imitaran y jugaran con ella” (Cantavella, 2011, p. 80).

Esta investigación, en suma, pretende contribuir al estudio del periodismo literario de aquellos años poniendo de relieve el romance periodístico como una de las aportaciones más originales de aquellas décadas que coloca en actualidad la tradición, no solo ya periodística y decimonónica, sino la de los máximos representantes del género, el Siglo de Oro y la Generación del 27 (Jiménez Losantos, 1995a).

12 El Cultural, 28 de febrero de 2001.

13 Para conocer más acerca de esta etapa de la biografía de Jaime Campmany, puede consultarse el artículo de Antonio Fernández Jiménez “Las 'Pajaritas de papel' de Jaime Campmany (1966-1970): aportación al periodismo literario español”, en Doxa Comunicación, № 24, 2017, pp. 179-171. Está disponible en línea, tanto en español como en inglés: http://dspace.ceu.es/handle/10637/8456

14 Entrevista a Emilio Campmany el 10 de diciembre de 2015. 


\section{DISERTACIONES}

ENSAYOS

Los desafíos del periodismo narrativo

ISSN: 1856-9536

Doi: https://doi.org/10.12804/revistas.urosario.edu.co/disertaciones/a.8462

Volumen 14, Número 1 / Enero-junio 2021

Versión PDF para imprimir desde

http://revistas.urosario.edu.co/index.php/disertaciones

\section{Metodología y fuentes}

A partir de 1978, la plena libertad de expresión devenida de la democracia marcó un punto de inflexión en el desarrollo del periodismo de opinión, que había comenzado a despuntar tímidamente desde la Ley de Prensa de 1966. Según Groshmann, citado por López Hidalgo, es en los años sesenta cuando "un nuevo periodismo comienza a gestarse" (2012, p. 20), aunque "no prolifera hasta la segunda mitad del siglo, experimentando su apogeo en la época posterior a 1975" (2012, pp. 15-16), cuando se asiste "a un auge sin parangón de la columna" (2012, p. 15). En este contexto enmarcamos este trabajo, pues es el período en que Campmany lleva a cabo su actividad periodística en $A B C$, donde llegó a escribir más de 15000 columnas bajo la sección Escenas parlamentarias y Escenas políticas desde el 26 de octubre de 1977 hasta el 13 de junio de 2005, el mismo día de su fallecimiento. La atractiva fórmula del romance periodístico nació en aquel diario, aunque la publicación en papel era más esporádica que la continuada rapsodia en la cadena cope.

Para elaborar este trabajo, se ha acudido a las fuentes primarias, es decir, a la bibliografía donde se recopila gran parte de los romances que escribió Jaime Campmany - tanto los publicados en ABC como los escritos para ser recitados en COPE-: El libro de los romances (1994), ${ }^{15}$ Segundo libro de romances (1995), El rey en bolas y otros romances (1997). De estos tres libros se han escogido romances más representativos y de distinta temática para su análisis. Con este objetivo, algunos han sido buscados en la hemeroteca digital de $A B C$, pues cuando se editaba un romance en el periódico no se publicaba con el formato vertical propio de versos octosílabos, sino que aparecía camuflado, "encajonado en la columna" (Jiménez Losantos, 1995a, p. 13). ${ }^{16}$

Como fuentes secundarias destacamos el acopio de material teórico-académico, como artículos científicos, monográficos, y también publicaciones de carácter periódico, que nos permiten contextualizar la situación del periodismo en el último tercio del siglo xx y llevar a cabo un análisis de los romances con la autoridad de autores expertos. Este trabajo cuenta también con el testimonio humano de la mujer de Campmany, Conchita Bermejo, y el de su hijo, Emilio Campmany; ambos conforman un archivo que podríamos llamar de la palabra: unas fuentes basadas en entrevistas en profundidad realizadas para la tesis doctoral defendida en 2017 en la Universidad de Murcia - de la que nace este artículo-. Dichos testimonios, y alguna conversación más reciente, se han usado para este trabajo, para no caer en imprecisiones y añadir un imprescindible cariz humano.

Como "las tipologías de género pueden ser infinitas [...] atendiendo a su temática, su funcionalidad, su estilo o su estructura" (López Hidalgo, 2012, p. 165), una posible categorización de los romances periodísticos podría situarse a partir de la división de la columna en dos grandes bloques que establece López Hidalgo: "En un primer bloque, incluiríamos todas aquellas columnas que son discursos; es decir, textos argumentativos. En un segundo bloque, aquellas columnas que son relatos, cuentos o poemas" (2012, p. 165), donde encontrarían cabida los textos que damos a conocer en este trabajo, los cuales, además, se pueden catalogar aún con mayor concreción si partimos

15 "Se vendieron casi más de cien mil ejemplares. Fue el libro que más vendió ese año", asegura Conchita Bermejo en la conversación mantenida el 6 de septiembre de 2018. Para este artículo, se está usando la novena edición, publicada en enero de 1995.

16 Dice Conchita Bermejo que "Jaime quería que lo descubriera la gente, lo hacía adrede". De la conversación mantenida el 6 de septiembre de 2018. 


\section{DISERTACIONES}

ENSAYOS

Los desafios del periodismo narrativo

ISSN: 1856-9536

Doi: https://doi.org/10.12804/revistas.urosario.edu.co/disertaciones/a.8462

Volumen 14, Número 1 / Enero-junio 2021

Versión PDF para imprimir desde

http://revistas.urosario.edu.co/index.php/disertaciones

de la subclasificación en cuatro modalidades que entiende Irene Andrés-Suárez: columna-noticia, columna-ensayo, columna-microrrelato, columna-poema en prosa. Mientras que las dos primeras nacen y reflexionan al hilo de la actualidad o motivadas por temáticas de distinta índole, la columna-microrrelato y la columna-poema en prosa poseen un cariz más emotivo, y es que "la naturaleza de estos textos creativos está más próxima a la literatura. Es decir, estamos hablando de géneros creativos" (Andrés-Suárez, citada por López Hidalgo, 2012, p. 165).

La muestra de los romances que se da a conocer en este trabajo va precedida por una apoyatura teórica necesaria que precisa las características bases de los romances periodísticos y que se apoya también en breves ejemplos; aunque será la muestra del apartado siguiente -cinco romances publicados entre los años 1988 a 1995- donde se materialice la praxis de lo expuesto en el análisis teórico. El análisis de los romances será visiblemente reconocido por estar en un recuadro con fragmentos de la muestra a un lado y comentarios (que no pretenden ser muy exhaustivos) a otro.

\section{Características del romance periodístico de Campmany}

\section{Estirpe clásica y virtuosismo léxico}

En el prólogo de El libro de los romances, Federico Jiménez Losantos destaca dos características esenciales del "verso campmanyano", a saber: estirpe clásica, es decir, dominio del género y de los clásicos "que llevaron el romance a la cumbre como expresión satírica" (1995a, p. 15); y el virtuosismo léxico, esto es, el manejo genial de la palabra, del vocabulario. En este sentido, afirma Juan Cantavella que es esta última una de las cualidades más apreciables de la prosa de Campmany: "[...] la riqueza léxica de que presumía, capaz de realizar un despliegue espectacular de palabras a propósito de cualquier materia o situación. Entonces sacaba a relucir los términos numerosos y jugosos que almacenaba en su mente, tanto provenientes del español culto como del coloquial, de las jergas y de los dialectos" (2011, pp. 80-81).

Estas dos primeras características están íntimamente engarzadas, pues Campmany "había leído a los clásicos [y] conservaba de aquellas lecturas tempranas y constantes la memoria de unas palabras que con suma frecuencia los demás olvidamos al cabo de poco tiempo" (Cantavella, 2011, p. 81). Campmany entendía que "la dificultad o el dolor del escritor al escribir se traduce, muchas veces, en la dificultad del lector al leer" y que una prosa barroca en "la precipitación de la frase trae de la mano espontaneidad y garbo, y favorece el ritmo de la lectura" (Casas \& Campmany, 1986, p. 6). De ahí que la facilidad que poseía Campmany a la hora de escribir provenga acaso de aquellos tiempos de juventud y lecturas en la biblioteca de su abuelo Emilio Díez de Revenga.

A veces, sin saber de qué voy a escribir, me siento, medito cinco o seis segundos y pongo un título. Considero que poniendo un título ya tengo más de la mitad del artículo escrito. A partir de ahí van naciendo ideas, saliendo cosas, asociando conceptos... y creo que esta facilidad se la debo al enorme caudal de lecturas que, desde joven, han pasado por mis manos. Leí y estudié mucho e incluso hubo una época en la que no era capaz de dormir sin haber leído un libro entero. Por eso ahora me resulta fácil escribir un artículo cada día, y a veces, incluso, dos o tres. ${ }^{17}$

17 Entrevista a Jaime Campmany por Marta Cano en El Faro de Murcia, el 13 de octubre de 2004, p. 9. 


\section{DISERTACIONES}

ENSAYOS

Los desafios del periodismo narrativo

ISSN: 1856-9536

Doi: https://doi.org/10.12804/revistas.urosario.edu.co/disertaciones/a.8462

Volumen 14, Número 1 / Enero-junio 2021

Versión PDF para imprimir desde

http://revistas.urosario.edu.co/index.php/disertaciones

Dice Jiménez Losantos que esa facilidad, “en periodismo, más que defecto, es necesidad” (1995a, p. 15). Conchita Bermejo cuenta que, si bien su esposo escribía las columnas en 20 minutos,$^{18}$ con el romance se recreaba más: "Le costaba más que el artículo porque le gustaba que fuera perfecto, que no le faltara una sílaba o un acento. A veces lo hacía a mano, con pluma. Le llevaba más tiempo, es natural. Hasta el punto de que le hicieron una proposición para escribir todos los días un romance y recitarlo en una radio, y Jaime dijo que no; que la columna le cuesta veinte minutos, pero que el romance le cuesta casi dos horas". ${ }^{19}$

El dominio del verso le hacía escribir indefectiblemente bien en prosa. De ahí que Cantavella exprese que los romances periodísticos poseen un ritmo frenético, pareciendo haber sido escritos "en cascada":

Cuando se pone a buscar sinónimos, cuando decide enjaretar un nombre o un adjetivo detrás de otro, cuando se lanza por la cuesta debajo de las enumeraciones (una acumulación retórica), entonces le salían en cascada y no había quien le hiciera parar, hasta el punto de que parece poseer un caudal inextinguible de términos, muchos de los cuales no los conocemos y hasta nos parece que se los está inventando, pero que vienen como anillo al dedo (2011, p. 81).

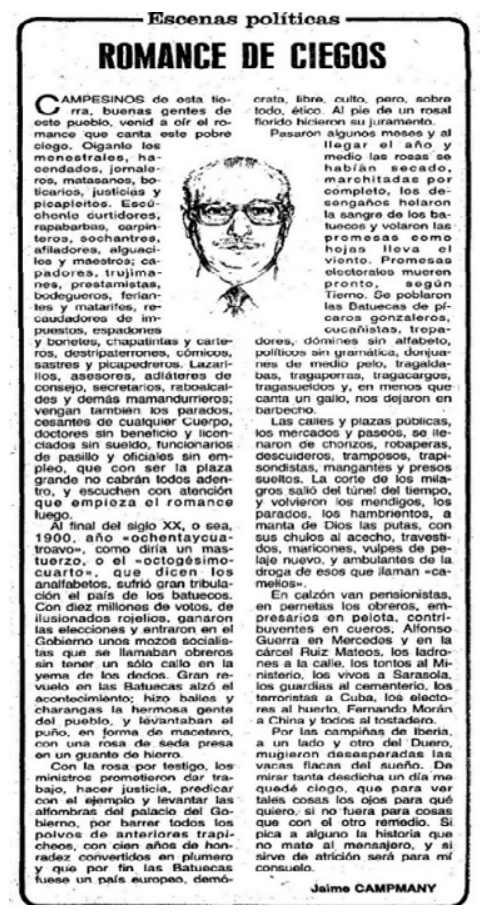

Figura 1. Copia extraída de la hemeroteca digital de abc del primer romance de Campmany, publicado el 15 de mayo de 1984, p. 17

18 "Jaime me decía que no servía para hacer el maratón y sí para los cien metros. El maratón era la novela y los cien metros, el artículo periodístico". Entrevista a Conchita Bermejo en mayo de 2014.

19 Conversación con Conchita Bermejo el 6 de septiembre de 2018. 


\section{DISERTACIONES}

ENSAYOS

Los desafíos del periodismo narrativo

ISSN: 1856-9536

Doi: https://doi.org/10.12804/revistas.urosario.edu.co/disertaciones/a.8462

Volumen 14, Número 1 / Enero-junio 2021

Versión PDF para imprimir desde

http://revistas.urosario.edu.co/index.php/disertaciones

Y con ese 'caudal inextinguible' pareció brotarle el primer romance a Campmany de forma involuntaria, sin ningún propósito más que el de escribir palabras en la hoja en blanco de un pequeño bloc de notas en un hotel de Cannes. Campmany "miraba y ganduleaba, dos ejercicios imprescindibles para llamar a la señora Inspiración" (Campmany, 1995b, p. 14). Era el 14 de mayo de 1984. Cogió un diminuto lapicero. "La anchura de la hoja del bloc apenas daba para escribir un octosílabo" (1995b, p. 14). Y sin pensarlo, empezó a componer los primeros versos de este romance:

\section{Campesinos de esta tierra /, buenas gentes de este pueblo, venid a oír el romance / que canta este pobre ciego. \\ Óiganle los menestrales, / hacendados, jornaleros, matasanos, boticarios, / justicias y picapleitos. \\ Escúchenle curtidores / rapabarbas, carpinteros, sochantres, afiladores, / alguaciles y maestros; capadores, trujimanes, / prestamistas, bodegueros, feriantes y matarifes, / recaudadores de impuestos, espadones y bonetes, / chupatintas y carteros, destripaterrones, cómicos, / sastres y picapedreros; lazarillos, asesores, / adláteres de consejo, secretarios, raboalcaldes / y demás mamandurrieros. ${ }^{20}$}

Campmany continuó escribiendo durante 40 minutos y un par de cafés, empleando el tono del romance tradicional, que mezcla lo sencillo, lo arcaizante y la fuerte carga semántica (Tomás Loba, 2009).

Al final del siglo xx, / o sea mil novecientos

año "ochentaycuatroavo", / como diría un mastuerzo,

o el octogésimo cuarto, / que dicen los alfabetos,

sufrió gran tribulación / el país de los batuecos.

Cuando lo terminó le preocupaban las dimensiones espaciales de la maqueta, pero cuando 'cantó' el romance al taquígrafo, este cuadró perfectamente en las palabras exactas del hueco de su columna diaria.

"Escrito así, a mano, en verso y en un pequeño bloc, era difícil calcular la dimensión del texto, y adivinar si llenaría la columna, sin faltas y sin sobras. [...] Llamé y canté. En cuarenta años de profesión periodística, había cantado por teléfono muchas crónicas. Por primera y única vez en mi vida, al terminar de dictar escuché un aplauso al otro lado de la línea. Era el taquígrafo, bendita sea su madre" (Campmany, 1995b, pp. 14-15).

El consenso y el aplauso del público devienen de la sencillez con que se produce la emoción literaria. Porque la fuerza de un artículo, de una columna o de un romance periodístico no reside en el malabarismo de las palabras. "No se trata de juegos verbales, de un simple ejercicio de estilo, sino una forma de cautivar al lector para trasladarle [...] un punto de vista persuasivo para obtener su adhesión sobre una determinada forma de entender la realidad" (Gross, 2010, p. 123).

$20 A B C, 15$ de mayo de 1984, p. 17. 


\section{DISERTACIONES}

ENSAYOS

Los desafíos del periodismo narrativo

ISSN: 1856-9536

Doi: https://doi.org/10.12804/revistas.urosario.edu.co/disertaciones/a.8462

Volumen 14, Número 1 / Enero-junio 2021

Versión PDF para imprimir desde

http://revistas.urosario.edu.co/index.php/disertaciones

\section{Humorismo y humanidad}

Cuando Luca de Tena le encomendó la crónica parlamentaria, Campmany se sentía casi un advenedizo al escribir de política. Después de muchos años podía hablarse con libertad sobre la vida política del país. No obstante, Campmany prefirió por acabar 'refugiándose en la literatura de humor':

Cuando empecé a escribir de política me refugié en la literatura de humor sin haberla practicado. Nunca he sido un escritor ni de ironía, ni de humor. Pero de una manera instintiva, porque tampoco me lo propuse, pensé que plantearle a la gente un drama diario criticando a los políticos o plantearle a los políticos la molestia de estar zahiriéndolos todos los días era una cosa excesiva. Entonces me refugié en la broma.

A veces molesta más, pero ahí ya no tengo la culpa. No es lo mismo llamarle a un tío cobarde que decir:

"Este es un cid de la pluma".21

Optando por la vía del humor, y aun siendo igual de contundente en las argumentaciones y razonamientos, Campmany da a sus romances "una apariencia de lenidad, porque suaviza los contornos y provoca la sonrisa (y hasta es posible llegar a la carcajada). Es más fácil prevenir el enfado de los demás cuando las cosas se dicen de manera jacarandosa" (Cantanvella, 2011, p. 82). La profesora de la Universidad de Piura María Fabiola Morales Castillo abordó ya hace unas décadas en su tesis doctoral El recurso del humor en el periodismo de opinión. Análisis de las columnas periodísticas "Escenas políticas" (1987), los rasgos humorísticos en las columnas de Campmany. El núcleo de aquel trabajo se basa en que "la persuasión del lector se busca por la vía del delectare, para conseguir la simpatía del público hacia el discurso, mediante el humor que está emparentado con el 'ethos', es decir, con los 'afectos suaves' de la retórica". ${ }^{22}$ Jaime Campmany es un prototipo de ese humor que también ha caracterizado a sus coetáneos y colegas de profesión, como Alfonso Ussía, Manuel Alcántara o Mingote.

Morales presenta a un Jaime Campmany desenfadado que crea un mundo cómico y escribe "con un saludable humor, instalado en un confortable cuarto de estar por el que desfilan esposa, suegra, tata Felisa e hijos en un diálogo que se presta a comentar la vida hogareña y la vida política". ${ }^{23}$ De hecho, Conchita Bermejo reflexiona: "Yo se lo decía muchas veces: 'Saca cosas de tu familia porque a la gente le gusta. Si todos los días escribieras de eso, pues no, pero a los lectores les gusta saber de cuando en cuando que tienes una tata, que de pequeño te decía cariño de col'. Que eso le daba humanidad al texto. También tenía en los artículos mucha socarronería murciana. Él me decía: 'Yo lo que tengo, que nadie lo comprende, es la mala lechecica murciana, que es buenísima’”."

21 Entrevista a Jaime Campmany en $A B C$ de Sevilla, 10 de mayo de 2005, p. 58.

22 Luisa Santamaría tiene un artículo, "El humor de Jaime Campmany: tema de una tesis doctoral", donde analiza el núcleo de la tesis de Morales (Actas del Congreso sobre Vigencia del Periodismo Escrito en el Entorno Digital Multimedia, 2001. http://pendientedemigracion.ucm.es/info/emp/Numer_07/7-6Bibl/7-6-04.htm).

23 Idem.

24 Entrevista a Conchita Bermejo, en mayo de 2014. 


\section{DISERTACIONES}

De sus años de infancia también es destacable la influencia de su bisabuela Laura Vicente (1851-1942), sobrina del poeta satírico José Selgas, quien enseñaba y transmitía al pequeño Jaime poemas, dialectalismos, epigramas y dichos. De ahí que la cite en algunos de sus romances para recurrir a su forma de hablar. ${ }^{25}$

En suma, las características expuestas las subraya el periodista Alfonso Ussía cuando dice de Campmany que es "zumbón y místico, quevedesco sublime, florentino de sabiduría adquirida, botánico del verbo y de la vida, dulce y terrible, alto señor y nunca villano, escritor excepcional". ${ }^{26} \mathrm{Y}$ aduce que, si en el Siglo de Oro la columna periodística hubiese estado en boga, “Cervantes, Góngora, Quevedo, Lope y Villamediana serían los columnistas clásicos. La columna periodística es un género literario de arte mayor, de riesgo mayor y de dificultad mayor. Mantener la maestría, la gracia, la ternura, el interés y el acierto día tras día no está al alcance de los mediocres. Y de los grandes, el más admirado y leído, es Jaime Campmany" (1992, pp. 17-19).

\section{Ejemplos de romances}

Que los romances de Campmany gozaran de gran popularidad y que los clasifiquemos como columnas-microrrelatos-poemas es debido, en parte, al empleo de la primera persona y al estilo narrativo encumbrado por la emoción literaria. Como dice José Julio Perlado, se establece una estrecha relación entre dos sujetos: "El columnista mantiene una cita periódica con sus lectores [...] en la columna el ‘yo' del autor no sólo es insustituible, es más: su sello de identidad" (Perlado, citado por López Hidalgo, 2012, pp. 43-45). Dice Andrés-Suárez que las columnas-poema en prosa "plasman por lo general momentos de gran intensidad emocional y constituyen verdaderas efusiones líricas transmitidas en primera persona gramatical” (Suárez, citada por López Hidalgo, 2012, p. 165).

Veamos algunos ejemplos.

25 Fragmento de Romance del bellotari, recitado en cope el 17 de junio de 1993 y publicado en El libro de los romances (1995, pp. 154-155).

26 Del prólogo de Alfonso Ussía al libro de Campmany Cartas batuecas, p. 17. 


\section{Una fábula mítica y real}

Romance
Romance del pararrayos

En el monte está Daniel cuidando de su ganado cuando la tormenta deja los cielos emborregados, las nubes enfurruñadas y los cirros enzarzados en lucha de culebrinas y en batalla de chispazos. Lanza chuzos encendidos el eléctrico aparato, y algunas cabras medrosas abandonan el rebaño y van por el monte solas, triscando llenas de pánico.

De pronto, desde la altura, desciende la luz de un rayo y va a dar en el pastor justo sobre el omoplato. Hiende el hombro, cruza el pecho, pasa muy cerca del brazo, se mete en el intestino, entra en terreno vedado, y sale por la morronga en forma de chufletazo cálido, ardiente, encendido, incandescente, abrasado.

Si el suceso fue en Cambrón, es de lógica obligado que nuestro Daniel quedara un poquito encambronado, pero fuerte como un toro y bien dispuesto al asalto, que rayo que no derriba será Rayo Vallecano o habrá sido Rayo X, que te traspasa sin daño. [...] Desde entonces, la dichosa zagala del enrayado, cuando quiere retozar con el pastor algún rato, suspira: "Venga, Daniel, levanta ya el pararrayos" (1997, pp. 135-138).

\begin{tabular}{c} 
Comentarios \\
\hline Recitado en Cope el 12 de mayo de 1995
\end{tabular}

Un extraordinario suceso ocurrido en la localidad cacereña de Cambrón inspiró a Campmany para relatar en un romance la historia de un pastor que cuidaba de sus cabras y al que, de pronto, en medio de una tormenta, le cayó un rayo que le entró por su hombro, recorrió su cuerpo y acabó saliendo por sus testículos. Sorprendentemente el hombre quedó ileso. ${ }^{27}$

Los primeros versos nos adentran a un escenario pastoril y bucólico. El uso de adjetivos ayuda a la recreación imaginaria del paisaje: cielos emborregados, nubes enfurruñadas, cabras medrosas. El elemento perturbador de la tormenta rompe el sosiego pacífico de la campiña antes del primer punto seguido con la frase poética: cirros enzarzados en lucha de culebrinas.

El uso de una enumeración caudalosa con comas y de cinco adjetivos seguidos concede a la narración cierta celeridad y agilidad al momento clave del relato, a la acción principal: la descripción fugaz del recorrido de un rayo.

27 Esta información ha sido extraída de la noticia dada por ABC el 11 de mayo de 1995, p. 80. 


\section{Verborrea de improperios}

\begin{tabular}{c|c} 
Romance & Comentarios \\
\hline Romance del chocholo & cope, 19 de octubre de 1992 \\
\hline
\end{tabular}

El señor ministro tiene lengua de lírico arroyo, trino de pájaro lira o de ruiseñor canoro y derrite al personal cuando le dice piropos. [...] Sin dejar el miramiento que hace a los hombres modosos, usando un vasco remilgo por mostrarse melindroso, con la sonrisa más tierna jugueteándole el bozo e inclinando el espinazo en gesto ceremonioso, boquirrubio y boquimuelle, boquilindo y boquiblondo, les llamó a los periodistas, dulcemente, mentirosos, a más de llamarles memos y sobre todo chocholos.

Recibamos con modestia el ministerial responso. Pero el único matiz que yo al ministro reprocho es que nos diga en vascuence lo que quiere decir "tonto", que es palabra castellana de abolengo muy remoto. $Y$ para darle una muestra de otros vocablos sinónimos, ahí va una pequeña sarta que le dedico gozoso: majagranzas, alcornoque, cascaciruelas, zurriburri, pelahuevos, parapoco, correlindes, papatoste, marmolillo, zampabollos, badulaque, chuchumeco, desavisado, zambombo, embelecado, guillote, rascatripas y tolondro, que aún me dejo en el tintero al lelo, al simple y al bobo. $Y$ tengo para seguir de este lunes hasta el otro, que donde las dan las toman, y en este país hermoso no hay ministro que me calle si uno me llama chocholo (1995a, pp. 99-100).
Muchos romances fueron emitidos en una cadena radiofónica. Los profesionales se dieron cuenta de que el romance podría "tener un feliz aprovechamiento en la radio; que si estaba bien lo que escribía para las páginas de un diario, mejor podría resultar si lo leyera de viva voz ante los micrófonos; que a la letra de aquellas cuestiones actuales [...] le vendría de perlas la música que desprende del romance" (Cantavella, 2011, p. 80). ${ }^{28}$ Así, Campmany 'pregona' la actualidad de la misma manera que hacían los primeros creadores de romances y la radio será el ambón desde donde declamará la gran mayoría de sus romances.

Este ejemplo es la réplica que hace a un político, el entonces ministro del Interior, José Luis Corcuera, quien había llamado chocholos a los periodistas, y Campmany le contesta desde un tono irónico y mostrando su virtuosismo en el empleo de múltiples términos castellanos, muchos de ellos no registrados por la Academia de la Lengua, como boquilindo o boquiblondo.
El político ha usado una palabra vasca de raigambre que viene a significar tonto, y Campmany aprovecha la ocasión para 'recomendarle' una serie de sinónimos para que apunte, al mismo tiempo que se los lanza, como contrarrespuesta. Un ejemplo más de ironía entreverada en esa verborrea sin parangón, que le hace a Campmany diferenciarse del resto de articulistas coetáneos.

Como explican García y Román, es precisamente en estas enumeraciones caóticas donde Campmany "muestra el énfasis, y la contención de la cantidad de temas y de argumentos que podría desarrollar. El léxico y el diferente uso de los niveles del lenguaje son de un dominio total" (2018).

28 "Le llamé cuando llegué yo a la cope en 1992 y le descubrí -recuerda Antonio Herrero en el prólogo del Segundo libro de romances de 1995-. Fantástico. Qué mala leche, qué ironía, vaya sopapos, qué dulzura con la lengua" (Herrero, 1995b). 


\section{Galimatías autonómico}

\begin{tabular}{c|c} 
Romance & Comentarios \\
\hline Romance panocho & abc, 27 de septiembre de 1994 \\
\hline
\end{tabular}

Si m'esclafo en er Senao

de senaor facundioso,

cuando prenuncie un discurso

lo platicaré en panocho, que es llengua de chirivía y galbanzos con mondongo en que platica mi suegra con su novio er tío Pacorro.

[...]

Er panocho en que sus hablo

no es panocho der cogollo, como se habla en Zaraiche y en la venta San Antonio, que va para munchos años que dejé aquellos rastrojos onde pasé tuiquio er tiempo de mamón y de mocoso, de zagalico crecío y aluego aluego, de mozo.

$Y$ m'hecho ya churubito d'escrebir en los periódicos, de hablar en los Escoriales, de recitar en el loro ese que llaman la COPE pus tós los días v'al copo, romanciquios de política y de darle leña al mono, que ya me salen las eses hista por los mesmos codos, y suerto cada remirgo con el "ido" y con "odo", con el "edo" y con el "ado" que si m'escuidio, me pongo más fino que una perdís, más tieso que un ajo porro, más lamío q'un magistrao y más dengue q'un canónigo. Digo "dedo" en vez de "deo" y en vez de "tó" digo "todo", y hasta "pedo" en vez de "peo" como icen los sabijondos.

Lo que motivó la escritura de este romance de tono crítico, irónico y humorístico fue el galimatías que se formó en el Senado cuando procedieron a hablar en sus lenguas autonómicas. Campmany aprovecha el asunto para usar el dialecto de su tierra, el murciano, más conocido como panocho, y así hacer una crítica emulando con gracia y chanza el guirigay sucedido.

En este caso se puede apreciar cómo Campmany, "con su enorme facilidad para tratar asuntos de actualidad, así como para dirigir sus dardos contra sus enemigos políticos, abordó en su columna política los asuntos públicos de la nación [...] con un gran sentido del humor" (García et al., 2018).

Vaya un cisco que s'armao en er Senao autonómico, tó dios hablando en su lengua $y$ tós los que escuchan, sordos, u teniéndolo que oír por la chicharra er micrófono. A la torre de Babel los llevaba yo en un soplo, y les daba masculillo, dimpués les daba un mamporro,

Esteban Morán dice que Campmany emplea a veces "un léxico popular lleno de encanto, salpicado de modismos regionales, de refranes, de sentencias, de vocablos olvidados, pero que están ahí, en el diccionario de la Academia" (1988, p. 180).

En este ejemplo podemos ver algunos localismos regionales, como "calichazo"; además del amplio predominio del sufijo diminutivo -ico: "tuiquio", "zagalico", "romanciquios"; o la deformidad de palabras, como "pulítica". El propio Campmany explica en ese fragmento cómo ha adquirido las terminaciones en -ido, -ado- y -odo por el hecho de vivir en un área geográfica como Madrid, en transición entre el dialecto septentrional y meridional.

y de postre un calichazo, un revés y un soplamocos a ver si aprenden a hablar como tóos hablamos, coño (1995b, pp. 199-202).

El ingenio y la ingenuidad expresan y ratifican de nuevo el carácter popular de esta original tipología de articulismo. El empleo de "tóos" en el último verso es una preclara manera de unificar coloquialmente las ricas variantes de España. 


\section{Políticos de hoy y siempre}

\begin{tabular}{c|c} 
Romance & Comentarios \\
\hline Romance de los ministros & copE, 22 de agosto de 1998 \\
\hline
\end{tabular}

Yo no sé qué tienen, madre, los ministros del Gobierno, que cuanto más los escucho, menos, madre, los entiendo. Oyes hablar a un ministro y caes en el desconcierto, pues con ellos nunca sabes, ni hay manera de saberlo, si te están hablando en broma o te están hablando en serio, si no saben lo que dicen o te están tomando el pelo. Yo no sé qué tienen, madre, los ministros del Gobierno, que donde ponen las manos se escachifolla el invento, al país le salen llagas donde ellos ponen el dedo, flor que tocan se deshoja y además rompen el tiesto; si alguna medida toman, que el tomar es siempre bueno, la toman tan a las malas que el traje les sale estrecho, pernicorto, corcusido, remendado y retalero, hecho de mangas por hombros y perneras por trasero, y visten a la criatura con hábito de adefesio. Yo no sé qué tienen, madre, los ministros del Gobierno, que ya no funciona nada en este bendito pueblo (1995a, pp. 21-22).

Es un retrato satírico de los políticos donde Campmany refleja el desconcierto y la preocupación que le hace interrogarse, desde un enfoque socarrón a la par que crítico, por qué los gobernantes utilizan un lenguaje, en ocasiones, críptico.

A un nivel más formal, hallamos de nuevo localismos murcianos, como retalero o pernicorto, y palabras o expresiones coloquiales nacionales, como adefesio, escachifolla, tomar el pelo. También frases hechas alteradas, como hecho de mangas por hombros $y$ perneras por trasero.

Cabe destacar la retórica literaria y la plasticidad expresiva en el uso de la personificación cuando, por ejemplo, alude a la imagen del país saliéndole llagas después de ser tocado por el dedo gobernante. 


\section{Romancero de la historia de España}

\begin{tabular}{c|c} 
Romance & Comentarios \\
\hline Romance del siglo $x x$ & Hoja del Lunes, 17 de julio de 1995 \\
\hline
\end{tabular}

Estaba el siglo en pañales,

la democracia en mantillas

y la edad de Alfonso XIII

no es edad de mayoría,

y así gobierna su madre, la reina María Cristina.

[...]

Habíamos perdido Cuba,

Puerto Rico y Filipinas,

aunque luego Isabel Preyler, que algunos llaman la China, ha compensado a Boyer

la pérdida de Manila.

[...]

Alfonso XIII se casa

y al pasar la comitiva

camino ya de palacio

la bomba de un anarquista

va a caer en la carroza

de la regia parejita.

Dentro de un ramo de flores

iba la bomba asesina,

que en Celtiberia te matan

tanto flores como espinas.

[...]

Publica Pérez Galdós

su Fortunata y Jacinta

y al mismo tiempo se acuesta

con la ardiente doña Emilia,

llamada Pardo Bazán,

que novelas escribía.

[...]

El siglo viene de estrenos.

$A B C$, en las rotativas,

y en la Zarzuela Chapí

estrena La patria chica.

Iglesias estrena escaño,

y don Eduardo Marquina

En Flandes se ha puesto el sol,

falda-pantalón las chicas,

y don Ramón Valle-Inclán

La princesa Rosalinda.

La venganza de don Mendo

a España mata de risa,

por culpa de Muñoz Seca, abuelo de Alfonso Ussía.

[...]

El treinta y cuatro corría.

La plaza del Manzanares

vive la hora más taurina,

y a las cinco de la tarde

a Ignacio Sánchez Mejías

lo llevan ya medio muerto

a su última enfermería.

Rafael Alberti le escribe liebre

en forma de elegía

a la orilla del mar Negro

en playas de Rumanía,

y a la gloria sube el Llanto

de Federico García.

Campmany destaca los hechos más representativos de toda una centuria. Su ambición era romancear toda la historia de España. En 2004, un año antes de su muerte, se publicó Romancero de la historia de España. De Atapuerca a los Reyes Católicos. Campmany pidió que no se le juzgara ni como poeta ni como historiador, "[...] en todo caso sería como juglar o trovero, pues estos romances no tienen el propósito de ir más allá del trovo o la juglaresca" (Campmany, 2004, pp. 13-14).

Este fragmento es un relato periodístico erigido como una gran efeméride. Construido desde un enfoque descriptivo, destaca los derroteros políticos sucedidos a lo largo de cien años, pero también resalta acontecimientos culturales y sucesos míticos que marcaron épocas. Todo relatado con rima, juglarescamente.

Como escritor del día a día y de los aconteceres del país en sus columnas, Campmany resume con la gracia propia de los versos octosílabos la historia de España del siglo XX.

Como explica María Lourdes Román Portas en su tesis doctoral sobre el valor retórico de las columnas de Campmany, "la intertextualidad es un recurso continuo en Campmany. Muestra sus lecturas, su cultura y la asimilación hechas de las mismas, y no hay columna en que no se encuentre alguna cita directa o encubierta. Se refiere sobre todo a los autores del Siglo de Oro, pero también destaca la Generación del 27" (2016, p. 297). 


\section{DISERTACIONES}

ENSAYOS

\begin{tabular}{c|c|}
\hline Romance \\
\hline Romance del siglo $x x$ \\
\hline
\end{tabular}

\begin{tabular}{|c|}
\hline Comentarios \\
\hline Hoja del Lunes, 17 de julio de 1995
\end{tabular}

Pasamos algunos años de clara germanofilia. Luego vino la victoria sobre la Europa nazista. Huyen los embajadores de la posguerra franquista, y sufrimos el bloqueo que nos castigó la tripa y decoró de gasógeno los minúsculos "balillas". [...]

Comienza la transición con la Reforma Política y se hacen el harakiri aquellas Cortes franquistas. [...]

El tricornio de Tejero puso una lámina antigua en la historia esperanzada de patria tan combatida, estampa que hace memoria del caballo de Pavía,

o del espadón de Loja, aquel que Narváez blandía (1997, pp. 261-276).

Como apunta Del Carmelo Tomás Loba, podríamos decir que Campmany canta el siglo. "La dualidad cantar trabajando o trabajar cantando ha sido siempre un pretexto agradable para [...] amenizar el momento con la variedad temática de que hace gala el romancero" (2009, p. 20).

En definitiva, Jaime Campmany fue un periodista relevante de la segunda mitad del siglo xx, que enriqueció a la profesión con sus escritos y se convirtió en cronista de un tiempo y de una España en constante transformación.

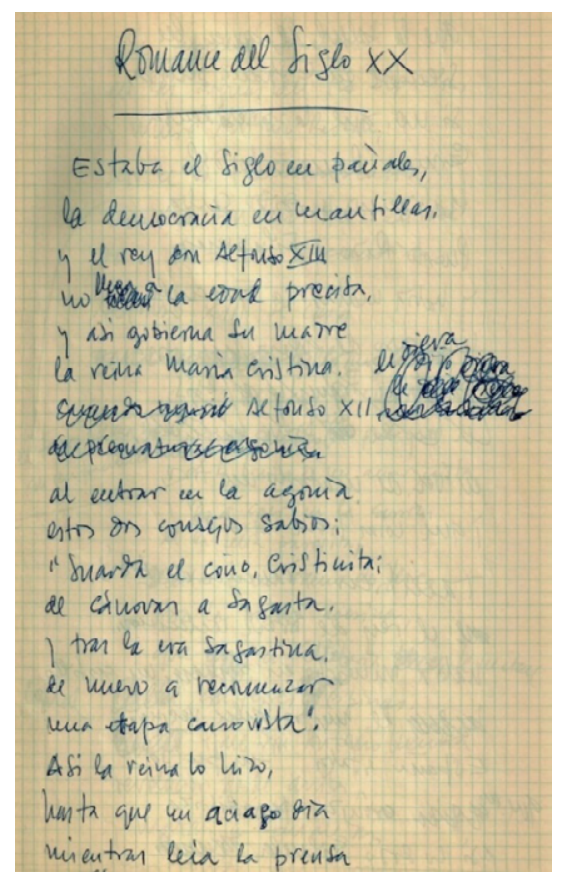

Figura 2. Borrador de Romance del siglo xx con correcciones de Campmany y escaneado del original facilitado por Conchita Bermejo 


\section{DISERTACIONES}

ENSAYOS

Los desafíos del periodismo narrativo

ISSN: 1856-9536

Doi: https://doi.org/10.12804/revistas.urosario.edu.co/disertaciones/a.8462

Volumen 14, Número 1 / Enero-junio 2021

Versión PDF para imprimir desde

http://revistas.urosario.edu.co/index.php/disertaciones

\section{Conclusiones}

El contexto periodístico que enmarca las décadas posteriores a la Transición democrática en España se caracteriza principalmente por la proliferación de un periodismo de opinión radicado especialmente en la columna y en el desarrollo de una escritura periodística de creación. Los romances periodísticos de Jaime Campmany en el último tercio del siglo xx se insertan en este período y suponen una preclara aportación al estudio de las relaciones de las disciplinas del periodismo y la literatura, y a la propia historia del periodismo literario en España con un modelo de periodista creativo como Jaime Campmany.

Cabe hacer hincapié en la importancia del estilo literario de este autor ejemplificado en estos romances periodísticos, pues el hecho de que este modo de hacer periodismo use las técnicas de la narrativa y de la literatura de ficción no significa que los recursos empleados, tales como la metáfora, la recreación de escenas o la descripción, caigan en una mera concepción de ornamento. Gracias a la fuerza poética impresa en estos textos, Campmany dotó al género periodístico de la columna de humanidad, profundidad y atemporalidad. De ahí que podamos encontrar en estos textos piezas que se consideren, una vez cumplida y pasada la actualidad en que se publicaron, imperecederas por su portento literario y útiles para comprender nuestra cultura y un determinado período de la historia de nuestro país. Y aunque él mismo decía de sí que era "solo un periodista, escritor de paso, romancero efímero, cronista de bengala" (1997, p. 23), quiso recopilar en libros, sin embargo, algunos de sus romances y también otras columnas que había escrito desde sus inicios en Madrid, porque sabía en el fondo que, aunque uno "destila palabras urgentes y a veces dolorosas, y las va tirando al agua. O las va echando a la hoguera. De vez en cuando, algunas de esas palabras merecen ser salvadas de la corriente o del fuego" (1997, pp. 12-13).

En definitiva, las características principales de estos romances, tales como la socarronería, la ironía, el virtuosismo léxico y el humor, así como la crítica argumentada, hacen palmaria en estos ejemplos la viveza de la libertad de expresión que se estrenaba en los años posteriores a la Transición. Además, la recuperación del romance de una tradición de periodistas versificadores actualiza toda una forma clásica de hacer periodismo en España que fue popular y emulada por otros periodistas. De ahí que este trabajo invite a la investigación sobre otros modelos de periodistas literarios que traspasaron su quehacer periodístico con una fuerte voluntad de estilo, 'fosilizando' en sus columnas y en sus crónicas una apasionante época del periodismo y de la historia de España.

\section{Referencias}

1. (26 de octubre de 1977). Jaime Campmany, en ABC. ABC, p. 25.

2. Albalad, J. M. (2018). Periodismo slow. O cómo se cuecen las historias en los fogones de Anfibia, Narratively $y$ FronteraD. Fragua-Biblioteca de Ciencias de la Comunicación.

3. Astorga, A. (10 de mayo de 2005). "A mi edad me lo puedo permitir todo". ABC (Sevilla), pp. 58-89.

4. Astorga, A. (14 de junio de 2005). Jaime I, el versificador. $A B C$, p. 12.

5. Campmany, J. (1992). Cartas batuecas. Ediciones Temas de Hoy.

6. Campmany, J. (1995a). El libro de los romances. Espasa.

7. Campmany, J. (1995b). Segundo libro de los romances. Espasa. 


\section{DISERTACIONES}

ENSAYOS

Los desafios del periodismo narrativo

ISSN: 1856-9536

Doi: https://doi.org/10.12804/revistas.urosario.edu.co/disertaciones/a.8462

Volumen 14, Número 1 / Enero-junio 2021

Versión PDF para imprimir desde

http://revistas.urosario.edu.co/index.php/disertaciones

8. Campmany, J. (1997). El rey en bolas y otros romances. Espasa.

9. Campmany, J. (2004). Romancero de la historia de España. De Atapuerca a los Reyes Católicos. La Esfera de los libros.

10. Cano, M. (13 de octubre de 2004). "No me arrepiento de una sola de las palabras que he escrito en mi vida". El Faro de Murcia, pp. 7-12.

11. Cantavella, J. (2011). La columna en verso: recuerdo y presencia de poetas y versificadores. Doxa Comunicación, (13), 67-83. http://dspace.ceu.es/bitstream/10637/5847/1/n\%C2\%BA\%20XIII_pp67_88.pdf

12. Casas, F. V., \& Campmany, J. (1986). La letra del cambio. Planeta.

13. Casasús, J. M., \& Núñez, L. (1991). Estilo y géneros periodísticos. Ariel.

14. Fernández, A. (2017). Entrevista a Conchita Bermejo. En El periodismo literario de Jaime Campmany (Tesis doctoral, Universidad de Murcia).

15. Fernández, A. (2017). Entrevista a Emilio Campmany. En El periodismo literario de Jaime Campmany (Tesis doctoral, Universidad de Murcia).

16. García, A., Lago, S., \& Román, M. L. (2018). El humor en la comunicación política: la Constitución española en la columna "Escenas políticas" de Campmany. Vivat Academia, (144), 51-67.

17. García, A., \& Román, L. (2018). El valor argumentativo de la enumeración en las columnas periodísticas de Jaime Campmany. Una aproximación cualitativa. Ámbitos. Revista Internacional de Comunicación, (40).

18. Gutiérrez, J. (2009). El 27: la edad de plata del periodismo literario. En J. Gutiérrez (Coord.), De Azorín a Umbral. Un siglo de periodismo literario español (pp. 334-409). Netbiblo.

19. León Gross, T. (Dir.), \& Gómez Calderón, B. (Ed.). (2008). El artículo literario: Manuel Alcántara. Universidad de Málaga.

20. León, T. (2010). La retórica del articulismo periodístico-literario. En M. Angulo \& J. M. Rodríguez (Coords.), Periodismo literario. Naturaleza, antecedentes, paradigmas y perspectivas (pp. 117-140). Fragua.

21. López Hidalgo, A. (2012). La columna. Periodismo y literatura en un género plural. Comunicación Social Ediciones y Publicaciones.

22. López Pan, F. (2008). La columna como paradigma de los géneros periodísticos de autor. En T. León Gross (Dir.) \& B. Gómez Calderón (Ed.), El artículo literario: Manuel Alcántara. Universidad de Málaga.

23. López, A. (26 de diciembre de 1982). "Soy muy buena persona”. La Verdad de Murcia, p. 6.

24. López, F., \& Gómez, B. (2010). El periodismo literario como sala de espera de la literatura. En M. Angulo \& J. M. Rodríguez (Coords.), Periodismo literario. Naturaleza, antecedentes, paradigmas y perspectivas (pp. 21-40). Fragua.

25. Menéndez Pidal, R. (1989). Flor nueva de romances viejos. Madrid: Espasa Calpe.

26. Morales, F. (1991). Recursos de humor en el periodismo de opinión. Análisis de las columnas periodísticas "Escenas políticas" (1987) (Tesis doctoral). Este facsímil ha sido producido por el Servicio de Reprografía de la Editorial de la Universidad Complutense de Madrid.

27. Morán, E. (1988). Géneros del periodismo de opinión. Crítica. Comentario. Columna. Editorial. Eunsa.

28. Román, M. L. (2016). La retórica del texto argumentativo en la columna de opinión "Escenas políticas" de Jaime Campmany (1983) (Tesis doctoral, Universidad de Vigo). 


\section{DISERTACIONES}

29. S. S., \& Servimedia. (11 de mayo de 1995). Sobrevive a un rayo que le entró por un hombro y le salió por los testículos. $A B C$, p. 80.

30. San Juan, J. B. (2009). El plan de desarrollo: el periodismo literario también crece. En J. Gutiérrez (Coord.), De Azorín a Umbral. Un siglo de periodismo literario español (pp. 569-617). Netbiblo.

31. Santamaría, L. (2001). El humor de Jaime Campmany: tema de una tesis doctoral. En Actas del Congreso sobre Vigencia del Periodismo Escrito en el Entorno Digital Multimedia. http://pendientedemigracion.ucm. es/info/emp/Numer_07/7-6-Bibl/7-6-04.htm

32. Tomás, E. D. C. (2009). Apuntes sobre literatura tradicional murciana. Real Academia Alonso X El Sabio.

33. Umbral, F. (28 de febrero de 2001). Jaime Campmany. El Cultural. http://www.elcultural.com/revista/ letras/Jaime-Campmany/2966

34. Vela, D. (2009a). Años ochenta: los ochenta son de los periodistas. En J. Gutiérrez (Coord.), De Azorín a Umbral. Un siglo de periodismo literario español (pp. 779-838). Netbiblo.

35. Vela, D. (2009b). La década del cambio: cinco años para finalizar, cinco años para empezar. En J. Gutiérrez (Coord.), De Azorín a Umbral. Un siglo de periodismo literario español (pp. 689-777). Netbiblo. 